\title{
THE METHOD OF DETERMINATION OF THE SORPTION CAPACITY OF ACTIVATED CARBON BY GAS CHROMATOGRAPHY
}

\author{
Ksenia Naumenko \\ Department of Food Expertise \\ National University of Food Technologies \\ 68 Volodymyrska str., Kyiv, Ukraine, 01601 \\ ksenianaumenko@ukr.net \\ Natalia Frolova \\ Department of Technology Health Products \\ National University of Food Technologies \\ 68 Volodymyrska str., Kyiv, Ukraine, 01601 \\ nef1956@mail.ru \\ Oksana Petrusha \\ Department of Foodstuff Expertise \\ National University of Food Technologies \\ 68 Volodymyrska str., Kyiv, Ukraine, 01601 \\ petrushaoo@ukr.net \\ Natalia Chepel \\ Department of Technology of Milk and Dairy Products \\ National University of Food Technologies \\ 68 Volodymyrska str., Kyiv, Ukraine, 01601 \\ natachepel@yandex.ua
}

\begin{abstract}
The article analyzes the possibility of gas chromatography use for determination of sorption capacity of adsorbents on the example of activated carbon BAC-A. The offered method provides the use of gas chromatograph with flame-ionizing detector and with nozzle geyser that is filled with studied adsorbent. At that the isotherms of absorption of substance are constructed by manifestation curve - desorption branch of substance peak on chromatogram.

As a result the isotherms of absorption of isoamylol and camphor on activated carbon were constructed and the values of specific sorption capacity for these substances were calculated.

This method allows receive fast and precisely the data about absorption characteristics of adsorbent and also adapt the conditions of the study using gas chromatography to the real conditions of adsorption of substances by studied adsorbent (temperature, adsorbent concentration in vapor phase and so on).
\end{abstract}

Keywords: gas chromatography, isotherm of adsorption, adsorption capacity, curve of adsorbate manifestation, isoamylol.

\section{Introduction}

The important parameter of exploitation properties of adsorbents, used in the catchers of aromatic substances of secondary vapor of juices and their extracts, is their sorption capacity. The absorption capacity is established for the concrete substances and expressed in units of mass or volume that can be maximally kept by adsorbent under certain conditions [1].

The static methods of constructing isotherms of adsorption by the weight (by increment of adsorbent mass after adsorption) or volumetric method (by the decrease of adsorbate amount in vapor phase after adsorption) are mainly used to determine the capacity of adsorbents [2]. Besides the static methods, the dynamic ones are widely used, and they allow assess the sorption capacity of adsorbent in time at permanent passing of absorbate flow through it [3, 4]. The dynamic ones include the method of determination of sorption capacity using gas chromatography. This method 
comparing with aforementioned ones allows establish the necessary conditions of the system "substance-adsorbent" - adsorption temperature, adsorbate concentration, speed of vapors movement through adsorbent and so on. That is why the method of gas chromatography was described and used for constructing isotherms of adsorption for the components that are in certain concentration in vapor phase $[5,6]$.

\section{Materials and Methods}

The method of determination of sorption capacity of activated carbon was based on the modeling of adsorption process by placing of studied adsorbent in nozzle geyser of gas chromatograph [6]. The metal nozzle geyser-concentrator with diameter $5 \mathrm{~mm}$, length $100 \mathrm{~mm}$ was used to construct isotherms of adsorption of gas chromatographic data and to optimize the process.

As it is known, the isotherm of adsorption $\mathrm{a}=\mathrm{f}(\mathrm{C})$ is a dependence of adsorption value $\mathrm{a}$ on balanced concentration of the substance $\mathrm{C}$. That is why the isotherms of adsorption are constructed on the base of integration for all kept volume of substance that corresponds to desorption branch of manifestation curve - peak of substance on chromatogram, presented on [7] (Fig. 1).

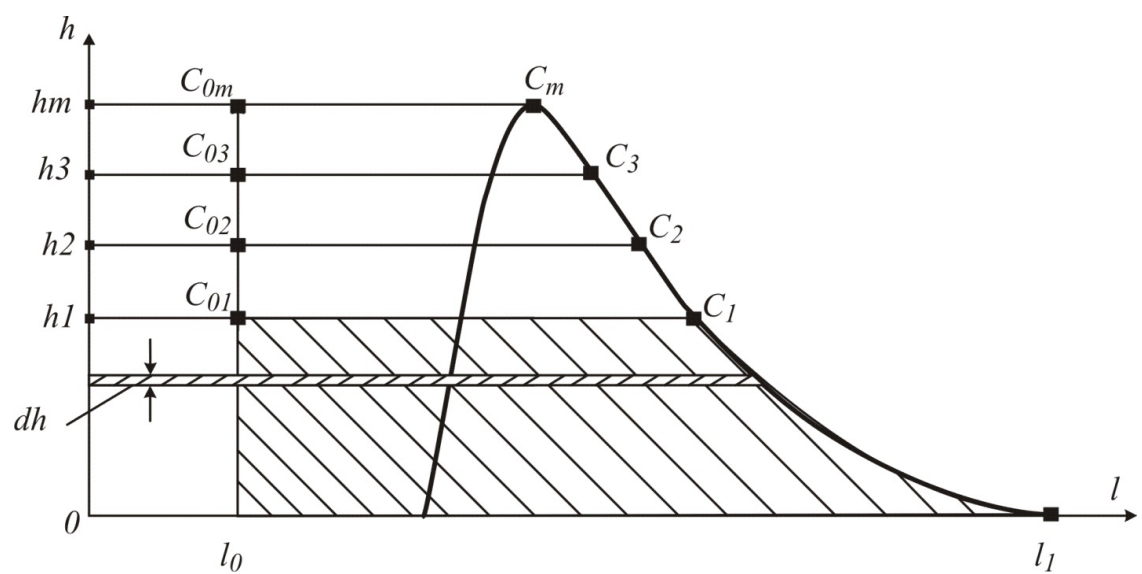

Fig. 1. The curve of manifestation of adsorbed substance, used for constructing isotherm of adsorption: $\mathrm{C}$ - concentration of substance in gas medium; $\mathrm{h}$ - response of detector signal, $\mathrm{mV}$ or $\mathrm{cm}$; $\mathrm{t}$ - time of keeping substance, $\mathrm{s}$ or $\mathrm{cm}$

The concentration of substance in gas medium corresponds to certain point on chromatographic peak, is proportional to the response of detector signal and is calculated by formula (1):

$$
\mathrm{C}=\mathrm{K} \cdot \mathrm{h},
$$

where $\mathrm{K}$ - constant of chromatograph, $\mathrm{mmol} / \mathrm{cm}^{3} \cdot \mathrm{cm}, \mathrm{h}$ - response of detector signal, $\mathrm{cm}$.

Determination of constant of chromatograph $\mathrm{K}$ was carried out using calibration on the base of dependence of peak area S on chromatogram on concentration of the substance q (2) [7]:

$$
\mathrm{q}=\int_{\mathrm{V}_{1}}^{\mathrm{V}_{2}} \mathrm{c} \cdot \mathrm{dw}=\int_{\mathrm{t}_{1}}^{\mathrm{t}_{2}} \mathrm{~K} \cdot \mathrm{h} \cdot \frac{\mathrm{a}}{\mathrm{u}} \cdot \mathrm{dt}=\frac{\mathrm{K} \cdot \mathrm{a}}{\mathrm{u}} \int_{\mathrm{t}_{1}}^{\mathrm{t}_{2}} \mathrm{~h} \cdot \mathrm{dt}=\frac{\mathrm{K} \cdot \mathrm{a}}{\mathrm{u}} \cdot \mathrm{S},
$$

where $\mathrm{S}$ - peak area, $\mathrm{cm}^{2}, \alpha$-gas-carrier speed, $\mathrm{cm} / \mathrm{min}, \mathrm{t}$ - absolute time of keeping substance, $\mathrm{cm}$, $\mathrm{w}-$ absolute volume of keeping substance, $\mathrm{cm}^{3} ; \mathrm{u}$ - constant that takes into account chromatogram scale, $\mathrm{cm} / \mathrm{min}$.

The constant of chromatograph at gas-carrier speed $27 \mathrm{~cm}^{3} / \mathrm{min}$ and constant $\mathrm{u} 0,4 \mathrm{~cm} / \mathrm{min}$ is determined by (2):

$$
\mathrm{K}=\frac{\mathrm{q} \cdot \mathrm{u}}{\alpha \cdot \mathrm{S}}=\frac{13,2 \cdot 10^{-6} \cdot 0,4}{27 \cdot 43,4}=4,4 \cdot 10^{-9}
$$


The mathematical description of equation of material balance of gas chromatographic process $[7,8]$ was used for determination of the amount of adsorbed substance

$$
-\alpha \cdot \frac{\partial \mathrm{C}}{\partial \mathrm{x}}+\mathrm{D} \cdot \chi \cdot \frac{\partial^{2} \mathrm{C}}{\partial \mathrm{x}^{2}}=\frac{\partial \mathrm{a}}{\partial \mathrm{t}}+\chi \cdot \frac{\partial \mathrm{C}}{\partial \mathrm{t}}
$$

where D - coefficient of longitudinal diffusion; $\chi$ - share of free cut of adsorbent - ratio of volume of intervals between seeds and the general volume of adsorbent in geyser; $\mathrm{C}$ - concentration of substance in flow, $\mathrm{mg} / \mathrm{cm}^{3}$; $\mathrm{a}$ - amount of adsorbed substance, $\mathrm{mg} / \mathrm{cm}^{3}$ by adsorbent; $\mathrm{t}$ - absolute time of keeping, min; $\alpha$ - speed of gas-carrier flow, $\mathrm{cm}^{3} / \mathrm{min} ; \mathrm{x}-$ distance from the beginning of adsorbed geyser-concentrator for the direction of gas-carrier flow, $\mathrm{cm}$.

Neglecting the diffuse erosion, that is accepting of the instantaneity of establishing balance of adsorption and desorption of substance, and having dependencies $\mathrm{a}=\mathrm{f}(\mathrm{C})$ and $\mathrm{c}=\mathrm{f}(\mathrm{t})$, the main equation (4) of chromatography was used in calculations in general form:

$$
\begin{gathered}
\frac{\partial \mathrm{x}}{\partial \mathrm{t}}=\frac{\alpha}{\frac{\partial \mathrm{a}}{\partial \mathrm{C}}+\alpha}, \\
\mathrm{a}=\frac{1}{\mathrm{~L}} \int_{0}^{\mathrm{c}}(\mathrm{VdC}-\mathrm{L} \cdot \chi \mathrm{dC}),
\end{gathered}
$$

where

$$
\begin{gathered}
\frac{\partial \mathrm{x}}{\partial \mathrm{t}} \approx \frac{\mathrm{x}}{\mathrm{t}} \approx \frac{\mathrm{L}}{\mathrm{t}}, \\
\chi=\frac{\mathrm{V}_{0}}{\mathrm{~L}},
\end{gathered}
$$

where $\mathrm{V}_{0}$ - volume of intervals between the seeds of adsorbent in geyser, $\mathrm{L}$ - length of geyserconcentrator [7].

At internal diameter of geyser-concentrator $5 \mathrm{~mm}$ takes place the general case of determination of amount of adsorbed substance a for $1 \mathrm{~g}$ of adsorbent according to (6):

$$
\mathrm{a}=\frac{\Delta}{\mathrm{g}} \int_{0}^{\mathrm{C}}\left(\mathrm{V}^{\mathrm{s}}-\mathrm{V}_{0}^{\mathrm{s}}\right) \mathrm{dC},
$$

where $\mathrm{V}^{\mathrm{s}}$ - gas-carrier volume at cross-cut $\mathrm{S}, \mathrm{g}$ - adsorbent batch, $\Delta$ - poured specific weight, $\mathrm{g} / \mathrm{cm}^{3}$.

Thus, the value of correspondent concentration of substance $\mathrm{C}$ is calculated by the indication of detector by formula (3). Taking into account the previous equations, the amount of adsorbed substance a was calculated by (7), (8):

$$
\begin{gathered}
\mathrm{a}=\mathrm{f}(\mathrm{C})=\frac{\alpha \cdot \mathrm{K} \cdot \Delta}{\mathrm{u} \cdot \mathrm{g}} \int_{0}^{\mathrm{h}}\left(1-\mathrm{l}_{0}\right) \mathrm{dh}=\frac{\alpha \cdot \mathrm{K} \cdot \Delta}{\mathrm{u} \cdot \mathrm{g}} \cdot \mathrm{S}, \\
\mathrm{a}_{\mathrm{m}}=\frac{\alpha \cdot \mathrm{K} \cdot \Delta}{\mathrm{u} \cdot \mathrm{g}} \cdot \mathrm{S}_{\mathrm{m}},
\end{gathered}
$$

where the area of peak fragment was calculated by (9):

$$
\mathrm{S}_{\mathrm{m}}=0 \mathrm{~h}_{\mathrm{m}} \mathrm{C}_{\mathrm{m}} \mathrm{l}_{1}-0 \mathrm{~h}_{\mathrm{m}} \mathrm{C}_{0 \mathrm{~m}} \mathrm{l}_{0}
$$

The reliable determination of adsorbents capacity was realized at temperature regime, correspondent to adsorption of aromatic substances at residual pressure $0,03 \ldots 0,07 \mathrm{mPa}$. The special 
nomogram UOP [9] was used for recalculation of temperature regime of absorption from the residual pressure $0,037 \mathrm{mPa}$ on atmospheric one. Since the stability of ratio between temperatures of boiling in vacuum and at atmospheric pressure is realized under condition of equal amount of vapors. According to the equation (10) the temperature of adsorption is calculated from the lowered pressure on atmospheric one:

$$
\frac{\mathrm{T}_{\mathrm{i}}}{\mathrm{T}_{\text {boil }}}=1+0,21 \cdot\left(\lg \frac{\mathrm{P}_{\mathrm{i}}}{\mathrm{P}}\right)+0,41\left(\lg \frac{\mathrm{P}_{\mathrm{i}}}{\mathrm{P}}\right)^{2}+0,004\left(\lg \frac{\mathrm{P}_{\mathrm{i}}}{\mathrm{P}}\right)^{3},
$$

where $\mathrm{T}_{\mathrm{i}}, \mathrm{T}_{\text {boil }}$ - the temperatures of boiling of equal amount of AS according to TTB curves at the low $\mathrm{P}_{\mathrm{i}}$ atmospheric $\mathrm{P}$ pressure, $\mathrm{K}$.

Thus, the parameters of experiment on determination of activated carbon capacity for aromatic substances are presented in the Table 1.

Table 1

The parameters of experiment on determination of BAC-A activated carbon capacity

\begin{tabular}{cc}
\hline Parameter & Value \\
\hline Temperature of evaporator of chromatograph & $200{ }^{\circ} \mathrm{C}$ \\
Temperature of adsorption (thermostat of geyser) & $100^{\circ} \mathrm{C}$ \\
Consumption of gas-carrier & $27 \mathrm{~cm}^{3} / \mathrm{min}^{-10}$ \\
Sensitivity of detector & $10 \cdot 10^{-10}$ \\
Amount of AS input & $0,1 \mathrm{mg}$
\end{tabular}

\section{1. Experimental procedures}

The object of research is the activated carbon BAC-A, that has an ability to adsorb the aromatic substances from water vapors, doesn't cause the chemical transformations of aromatic substances at adsorption and desorption, has developed active surface of pores $[2,10]$.

The physical-technical characteristics of activated carbon BAC-A are presented in the Table 2.

Table 2

The physical-technical parameters of activated carbon BAC-A

\begin{tabular}{cc} 
Parameter & Characteristic \\
\hline Specific surface, $\mathrm{m}^{2} / \mathrm{g}$ & $700 \ldots 800$ \\
Mean diameter of pores, $\mathrm{nm}$ & $\leq 200$ \\
Poured density, $\mathrm{g} / \mathrm{cm}^{3}$ & 0,161 \\
Size of seeds, $\mathrm{mm}$ & $0,5 \ldots 0,9$ \\
Temperature limit, ${ }^{\circ} \mathrm{C}$ & 300
\end{tabular}

The isotherms of adsorption on activated carbon were determined for such adsorbates as camphor with molecular mass $152,2 \mathrm{~g} / \mathrm{mol}$ and isoamylol with molecular mass $88 \mathrm{~g} / \mathrm{mol}$. 
The experiments were carried out on gas chromatograph Selmichrom-2003 (Ukraine) with flame-ionizing detector. The gas carrier was nitrogen.

The measuring was carried out in following way: the nozzle geyser-concentrator was filled with activated carbon BAC-A, and placed in thermostat of chromatograph, one end was connected with injector and other one - with detector, using connecting elements. The aromatic substance was inserted in injector of chromatograph by micro-syringe. The speed of nitrogen flow was established at the level $27 \mathrm{~cm}^{3} / \mathrm{min}$. As a result the partial pressure of substance in mixture "nitrogen-substance" decreases, its quantity is registered by detector and is recorded as the peak - adsorption. After balanced satiation at fixed concentration of adsorbate, the transmission of nitrogen through the geyser-concentrator continued. At that the emission of adsobate from the surface of adsorbent took place and its amount was recorded as the desorption peak. (Fig. 1).

The established parameters of experiment (Table 1) allowed receive the curves of manifestation of camphor and isoamylol at passing through the nozzle geyser, filled with activated carbon BAC-A. The value of concentration of substance in gas medium $\mathrm{C}, \mu / \mathrm{ml}$, and correspondent amount of adsorbed substance a on adsorbent $\mu / \mathrm{ml}$ were calculated by the points on manifestation curves.

\section{Results}

On the Fig. 2, 3 are presented the isotherms of monomolecular adsorption of isoamylol and camphor on activated carbon BAC-A.

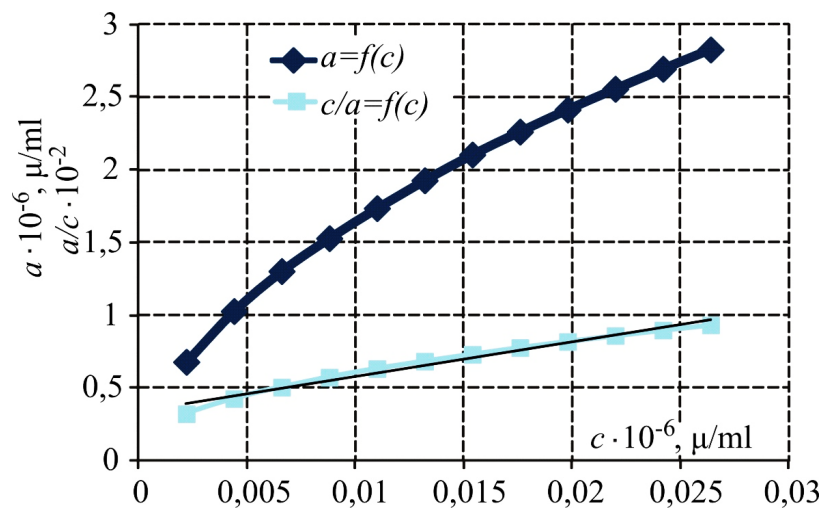

Fig. 2. Isotherm of adsorption of isoamylol on activated carbon BAC-A

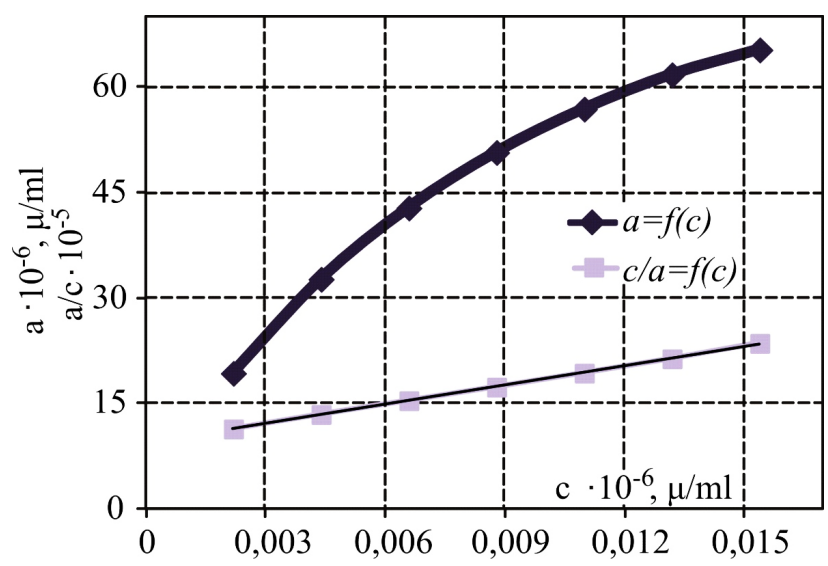

Fig. 3. Isotherm of adsorption of camphor on activated carbon BAC-A

The constructed isotherms allowed to determine their typicality for Lengmuir's monomolecular adsorption at isoamylol and camphor quantity in gas phase up to $0,1 \mathrm{mg}$.

The isotherm of adsorption is described by Lengmuir's equation according to (11): 


$$
\mathrm{a}=\mathrm{a}_{0} \cdot \frac{\mathrm{c}}{\mathrm{K}_{1}+\mathrm{c}}=\mathrm{a}_{0} \cdot \frac{\mathrm{p}}{\mathrm{K}_{1}+\mathrm{p}}
$$

where $\mathrm{a}_{0}$ - capacity of mono-layer; $\mathrm{p}$ - partial pressure of adsorbate; c- concentration of adsorbate in vapor phase; $\mathrm{K}_{1}$ - constant that depends on temperature and type of adsorbent and is a constant value for couple adsorbent-adsorbate, numerically equal to adsorbate concentration, at which the half of active centers of adsorbent is occupied [11].

The graphic solution of Lengmuir's equation (11) by transformation of isotherm of adsorption of the type $\mathrm{a}=\mathrm{f}(\mathrm{c})$ into the direct one of the type $\mathrm{c} / \mathrm{a}=\mathrm{f}(\mathrm{c})$ determine cotangent of inclination angle that is equal to the capacity of mono-layer of activated carbon for isoamylol and camphor.

The results of calculation of specific weight of adsorption capacity of activated carbon are presented in the Table 3.

Table 3

The values of specific adsorption capacity of activated carbon BAC-A

\begin{tabular}{ccc}
\hline Adsorbate & \multicolumn{2}{c}{ Specific weight of mono-layer } \\
& $\times \mathbf{1 0}^{-6} \mathbf{m} \mathbf{m o l} / \mathbf{c m}^{\mathbf{3}}$ & $\mathbf{M g} / \mathbf{g}$ \\
\hline Isoamylol & 3,96 & 1,97 \\
Camphor & 109,45 & 103,47
\end{tabular}

The relative error at measurement and calculation of the value of specific adsorption capacity of adsorbent was no more than $2,5 \ldots 2,8 \%$.

The received data of calculations indicate the difference of specific sorption capacity of activated carbon for camphor and isoamylol that is explained by the differences at "adsorbentabsorbate", interaction seizes and polarity of molecules of camphor and isoamylol.

\section{Conclusions}

The results of research allowed to receive the value of specific sorption capacity of activated carbon BAC-A for isoamylol and camphor that has practical importance in calculation of the optimal quantity of adsorbent for adsorption of aromatic substances of extracts, juices. At the same time depending on the fractional composition of aromatic substances and taking into account the selectivity of adsorbents their quantity can be optimized. Thus, the activated carbon is more selective to camphor $(103,47 \mathrm{mg} / \mathrm{g})$ than to isoamylol $(1,97 \mathrm{mg} / \mathrm{g})$.

Analyzing the realized studies, the following advantages of using gas chromatography for determination of sorption capacity of adsorbents must be noted:

- exactness of method, proved by the high sensitivity of detector of chromatograph;

- flexibility of conditions of researches: possibility to change the temperature of adsorption, adsorbent, adsorbate and its concentration in vapor phase.

The disadvantages include:

- complexity of calculations for construction of isotherms of adsorption:

- complication of the study of adsorption of AS with high boiling temperature by the "erosion" of desorption curve.

Taking into account the aforesaid, the further studies can be directed on widening of spectrum of studied adsorbents and their aromatic substances.

\section{References}

[1] Ekymova, Y. A., Mynakova, T. S. (2013). Adsorbtsyonnye yssledovanyia parov vody na oksydakh y ftorydakh shchelochnozemelnykh metallov y mahnyia. Natsyonalnyi yssledovatelskyi Vestnyk THASU, 2, 263-275. 
[2] Andryiantseva, S. A., Bondarenko, A. V., Petukhova, H. A. (2012). Ekspress-metod yssledovanyia yzotermy adsorbtsyy benzola uhlerodnymy hydrofobnymy materyalamy. Sorbtsyonnye y khromatohrafycheskye protsessy, 12 (1), 114-118.

[3] Vagner, C., Finqueneisel, G., Zimny, T., Weber, J. (2002). Water vapour adsorption on activated carbons: comparison and modelling of the isotherms in static and dynamic flow conditions. Fuel Processing Technology, 77-78, 409-414. doi: 10.1016/s0378-3820(02)00090-5

[4] Ivanova, E., Karsheva, M. (2007). Ethanol vapours adsorption by natural clynoptilolitee. Journal of the University of Chemical Technology and Metallurgy, 42, 391-398.

[5] Kondor, A., Dallos, A. (2014). Adsorption isotherms of some alkyl aromatic hydrocarbons and surface energies on partially dealuminated $\mathrm{Y}$ faujasite zeolite by inverse gas chromatography. Journal of Chromatography A, 1362, 250-261. doi: 10.1016/j.chroma.2014.08.047

[6] Viacheslavov, A. S., Efremova, M. (2011). Opredelenye ploshchady poverkhnosty y porystosty materyalov metodom sorbtsyy hazov. Moscow: MHU ym. M. V. Lomonosova, 65.

[7] Viakhyrev, D. A., Shushunova, A. F. (1987). Rukovodstvo po hazovoi khromatohrafyy. Moscow: Vysshaia shkola, 335.

[8] Scott, R. (2003). Principles and practice of chromatography. Library for science, 106.

[9] Khafyzov, F. Sh., Krasnov, A. V. (2012). Davlenye nasyshchennykh parov dlia nefteproduktov. Elektronnyi nauchnyi zhurnal «Neftehazovoe delo», 3, 406-412.

[10] Naumenko, K. A., Frolova, N. E., Ukrainets, A. I., Usenko, V. O. (2010). Selection and estimation of adsorbents for catching of aromatic substances during the concentration of juices and extracts. Naukovi pratsi NUKhT, 33, 8-16. 